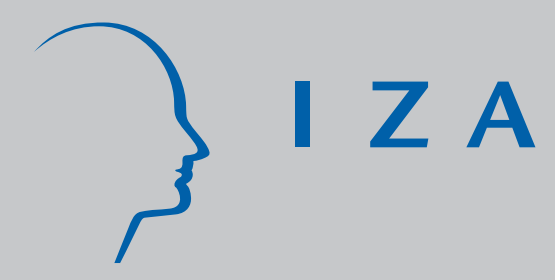

IZA DP No. 950

Equilibrium Employment in a Model of Imperfect Labor Markets

Pietro Garibaldi

Etienne Wasmer

December 2003 


\title{
Equilibrium Employment in a Model of Imperfect Labor Markets
}

\author{
Pietro Garibaldi \\ Bocconi University, IGIER, \\ CEPR and IZA Bonn \\ Etienne Wasmer \\ ECARES, Free University of Brussels, \\ University of Metz, CEPR and IZA Bonn \\ Discussion Paper No. 950 \\ December 2003
}

\author{
IZA \\ P.O. Box 7240 \\ D-53072 Bonn \\ Germany \\ Tel.: +49-228-3894-0 \\ Fax: +49-228-3894-210 \\ Email: iza@iza.org
}

This Discussion Paper is issued within the framework of IZA's research area Mobility and Flexibility of Labor. Any opinions expressed here are those of the author(s) and not those of the institute. Research disseminated by IZA may include views on policy, but the institute itself takes no institutional policy positions.

The Institute for the Study of Labor (IZA) in Bonn is a local and virtual international research center and a place of communication between science, politics and business. IZA is an independent, nonprofit limited liability company (Gesellschaft mit beschränkter Haftung) supported by Deutsche Post World Net. The center is associated with the University of Bonn and offers a stimulating research environment through its research networks, research support, and visitors and doctoral programs. IZA engages in (i) original and internationally competitive research in all fields of labor economics, (ii) development of policy concepts, and (iii) dissemination of research results and concepts to the interested public. The current research program deals with (1) mobility and flexibility of labor, (2) internationalization of labor markets, (3) welfare state and labor market, (4) labor markets in transition countries, (5) the future of labor, (6) evaluation of labor market policies and projects and (7) general labor economics.

IZA Discussion Papers often represent preliminary work and are circulated to encourage discussion. Citation of such a paper should account for its provisional character. A revised version may be available on the IZA website (www.iza.org) or directly from the author. 
IZA Discussion Paper No. 950

December 2003

\section{ABSTRACT \\ Equilibrium Employment in a Model of Imperfect Labor Markets*}

This paper presents a simple model of imperfect labor markets with endogenous labor market participation and home production. We show that a two-sector economy (home and market) implies a three-state labor market when labor market imperfections take the form of an irreversible entry cost incurred by workers. This simple framework brings several results. First, it delivers an expression for the employment rate and as side-products, a measure of the unemployment rate and the size of the labor force. Second, it rationalizes several empirical works on the definition of unemployment in labor force surveys. Third, it derives endogenously all flows between three labor market states. Fourth, a calibration of the model rationalizes differences in employment rates: in the U.S., we find a market productivity premium of $+30 \%$ and market frictions of $-15 \%$ compared to France. Finally, the model is a very simple reduced form of search models with which it is fully consistent: the irreversible entry cost is the opportunity cost of search and depends on aggregate conditions.

JEL Classification: J21

Keywords: employment, non-employment, labor market participation, frictions

Corresponding author:

Etienne Wasmer

ECARES

Université Libre de Bruxelles

CP 114

Avenue Franklin D. Roosevelt 39

1050 Brussels, Belgium

Tel.: +32 26504212

Fax: +3226504475

Email: ewasmer@ulb.ac.be

\footnotetext{
* Paper presented at the UQAM-CIRPEE conference on Labor Market Frictions and Macroeconomic Dynamics on October 3rd and 4th 2003 and at the IZA workshop on search and matching models on November 14th and 15th 2003. We thank all participants and our discussants, notably Michael Pries and Giuseppe Bertola for insightful discussions, and Ken Burdett for expertise on wage posting.
} 


\section{Introduction}

Cross-country differences in employment rates are very large, ranging in 2002 from $55 \%$ of the $15-64$ population in Italy to $63 \%$ in France, $71.5 \%$ in the United Kingdom and $76 \%$ in the US. Further, cross-country differences in unemployment rates cannot account for such differences, mostly due to different participation behavior. Some have analyzed these crosscountry differences within the context of the neo-classical labor market model ${ }^{1}$, but market imperfections are difficult to ignore when discussing low employment in European countries, where the mean duration of unemployment is about or above one year. However, we lack a good benchmark to analyze equilibrium employment to population rates.

Our paper proposes a simple theory of employment rates with market frictions. We then attempt to account for the wide cross-country differences in employment rates with imperfections in labor markets driving the participation strategies of workers. A general difficulty in this task is that the working age population is partitioned into different categories for which frontiers are not always precisely defined. There is a well defined population who has a job in the labor market, a well defined population that do not work in a formal market and do not want to work in the labor market, and there is a third category of individuals that would want a job at the market wage but don't have one. In the latter category, which can be called extended unemployment, one finds both individuals actively seeking for a job which broadly corresponds to the ILO definition of unemployment ${ }^{2}$, and individuals that do not search for a job but, if they had one, would accept it. The latter correspond to a sizeable group that Jones and Riddel (1999) call marginally attached to the labor market. These studies and others ${ }^{3}$ indicate that labor force participation and attachment to the labor market are difficult to observe and to define.

In this paper we present a simple model of the labor market with both market imperfections and home production. ${ }^{4}$ Home production (or equivalently, the utility from being at home) differs across individuals and evolves stochastically in time, which drives decisions to participate. Labour market imperfections differ from conventional studies: they are not based on market power of workers driving wages above the reservation wage, nor they are based on asymmetries of information. They are instead modelled in the spirit of search mod-

\footnotetext{
${ }^{1}$ See Prescott (2002) for France-US differences.

${ }^{2}$ In addition, the definition requires worker to be immediately available for a job and have not been employed during the week of the survey.

${ }^{3}$ In earlier insightful studies, Sorrentino (1993 and 1995) has measured these different notions of unemployment across countries and revealed important differences in rates according to the definition chosen.

${ }^{4}$ Following the seminal paper of Becker (1988), the time allocation problem of core macroeconomics considers both the time to be spent in the market and the time to be spent in household production.
} 
els, as an irreversible entry cost paid by workers upon their entry into the labor market. This drives a wedge between the entry into the labour market and exit from the market, so that labour force participation is described by two margins. ${ }^{5}$

Our results are as follows. First, we derive the employment rate, a measure of extended unemployment rate, and their complement in the working age population, which we call the pure non-employment rate. The latter declines with market frictions and market productivity, while the employment rate is increased by market productivity. Second, the paper distinguishes between two types of non-employed workers: people without a job but willing to work at the equilibrium wage, and people without a job that are not willing to work, in a way consistent with the work of Jones and Riddel (1999). Third, we derive endogenously all flows between the employment, extended unemployment and out of the labour force. Fourth, we show that a calibration of the model can rationalize differences in employment rate between France and the United States, with a market productivity that is 30 percent higher than average home productivity in the United States, while it is roughly comparable in France. Our calibration also indicates that market frictions are equal to 1.6 month of market output in France, while they are roughly equal to 1.4 month of output in the United States. Finally, we show that labour market search is fully consistent with our irreversible entry costs: the entry costs can be easily rationalized as the expected value of forgone home productivity during search activity.

The paper proceeds as follows. Section 2 proposes a baseline model of market frictions, home production and endogenous market participation. Section 3 derives the reservation strategies of workers, the participation margins and the stock and flows in the labour market. Section 4 uses the model to account for cross-country differences in employment and nonparticipation. Section 5 discusses other implications of the model, notably dual labor market theory and the links to search theory. Section 6 concludes.

\section{Set-up}

\subsection{Home and market production}

We assume that a mass one of individual derives utility from home production and market production. Individuals have a unit of time to be spent in market and home production. Capital markets are perfect and utility is linear in consumption. In utility terms, market production and home production are perfect substitute, so that individuals specialize in the

\footnotetext{
${ }^{5}$ The paper thus introduces the theory of irreversible investment (Dixit and Pindyck, 1994) to the analysis of the supply side of labor markets.
} 
activity in which they have an absolute advantage. Hours spent in the labor market are indivisible, and, for analytical simplicity, we normalize them to 1 , so that market production is a full time activity. ${ }^{6}$ Individuals take as given the wage for a full day in the market, and we indicate such wage with $w$. A job is a productive opportunity at the individual level that can be destroyed at rate $\delta$, where $\delta$ is the arrival rate of a Poisson process, so that a job lasts on average $1 / \delta$ periods. Utility from home production or equivalently productivity at home is heterogenous and stochastic and its value changes according to a Poisson at rate $\lambda$. A full day in home production yields a per period utility equal to $x$, where $x$ is drawn from a continuous cumulative distribution $F(x)$ defined over the support $\Omega=\left[x^{\min }, x^{\max }\right]$.

Workers decide how much time to spend in market and home production. Since the time spent in market production is indivisible, the model is an extensive margin model. In absence of frictions in the market the model is trivial and the participation decision is described by a single reservation value $x^{*}$, so that all individuals with home production below $x^{*}$ participate full time in market activity.

In reality, information on the location and the availability of jobs is not perfect, and the process of information gathering is akin to paying an irreversible cost. In what follows, we assume that each time an individual enters the labor market or gets a new job, he or she must pay a an irreversible cost equal to $\mathcal{C}$. As we will show in section 5.1, a traditional matching model with time consuming search, in the spirit of the work of Pissarides (1985) and Mortensen and Pissarides (1994), is identical to assuming that obtaining a job requires an irreversible entry cost.

\subsection{Value functions}

Let us indicate by $H$ the value function for being full time in home production and with $W$ the value function for being full time in market production. Formally, the value function of being in market activity reads

$$
r W(x)=w+\delta[\operatorname{Max}[W(x)-C ; H(x)]-W(x)]+\lambda\left[\int \operatorname{Max}[W(z), H(z)] d F(z)-W(x)\right]
$$

where $r$ is the pure rate of time preferences. The equation has a standard asset value interpretation. The value of having a job is equal to the wage $w$ plus two capital gain terms, each of them representing a participation decision from the worker stand-point. When a job is destroyed at rate $\delta$, a worker has to choose whether going to home production or getting

\footnotetext{
${ }^{6}$ It is easy to check that none of the properties of the model is affected when workers can produce $\left(1-h_{w}\right) x$ units of home production when they work $h_{w}$ inelastically supplied hours inthe market. We thus chose the simplest exposition with $h_{w}=1$.
} 
a new job. In the latter case, it is necessary to pay again the entry $\operatorname{cost} \mathcal{C}{ }^{7}$ When the home productivity changes at rate $\lambda$, the worker will get a new draw from the distribution $F$, and will choose whether at the new home productivity value continuing on the same job is optimal vis-a-vis switching to full time home production. Note that in the latter case there is no fixed cost to be paid. Similarly, the value of being full time in home production reads

$$
r H(x)=x+\lambda\left[\int \operatorname{Max}[W(z)-\mathcal{C}, H(z)] d F(z)-H(x)\right]
$$

where the right and side features a dividend equal to $x$ and an expected capital gain conditional upon drawing a new home productivity value at rate $\lambda$. In the latter case, the worker has to decide whether labour market participation is optimal.

\subsection{Labor supply and reservation strategies}

The existence of the irreversible $\operatorname{cost} \mathcal{C}$ induces a separation of the entry and exit decisions. We now show that the maximization problem is solved by two reservation strategies, represented by two cut-off points $x^{\nu}$ and $x^{q}$, defined as

$$
\begin{aligned}
& W\left(x^{\nu}\right)-H\left(x^{\nu}\right)=\mathcal{C}=S\left(x^{\nu}\right) \\
& W\left(x^{q}\right)-H\left(x^{q}\right)=0=S\left(x^{q}\right)
\end{aligned}
$$

where $x^{\nu}$ is the entry cut-off point and $x^{q}$ is the exit cut-off point, and $S(x)=W(x)-H(x)$. The quantity $S(x)$ is the surplus from employment for a worker at home productivity $x$. Using the difference of equations (1) and (2) and after a few steps of algebra, the surplus can be written as

$$
\begin{aligned}
(r+\delta+\lambda) S(x) & =w-x+\delta \operatorname{Max}[S(x)-\mathcal{C} ; 0] \\
& +\lambda \int \operatorname{Max}\left[S\left(x^{\prime}\right), 0\right] d F\left(x^{\prime}\right)-\lambda \int \operatorname{Max}\left[S\left(x^{\prime}\right)-\mathcal{C}, 0\right] d F\left(x^{\prime}\right)
\end{aligned}
$$

Equation (5) is piece-wise linear in $x$ and satisfies the reservation property (see Appendix for details).

\subsection{Labor demand}

The entry and the exit margins summarize the labour supply dimension of the model, and characterize the market behavior given the wage rate $w$. To close the model, we need to

\footnotetext{
${ }^{7}$ This assumption is not essential but simplifies a bit one of the expressions for the participation margins, and makes the interpretation of $\mathcal{C}$ easier in terms of search costs (Section 5.3).
} 
specify labour demand and derive the wage. In what follows we assume that there an infinite supply of potential entrepreneurs that can enter the market at any time. If they enter, they establish a firm and hire one worker, both at zero cost. The wage is determined as follows: the firm posts a wage which is never renegociated later on.

Denoting by $q$ the quit rate of employed workers faced by employers, the present discounted value of a filled job is

$$
J=\frac{y-w}{r+\delta+q}
$$

where $y$ is the value of the labour product and $w$ is the wage rate. Note that a job is discounted at rate $r+\delta+q$ since jobs are hit by destruction shock at rate $\delta$ and are similarly dissolved by endogenous quit at rate $q$, the value of which is determined later on.

The wage posting equilibrium is such that all profits are eliminated, i.e. $J \equiv 0$ and the corresponding wage is

$$
w^{*}=y .
$$

Indeed, there is no unilateral profitable deviation, in the sense that no job offer can be above $y$ (negative profits) or above $y$ (workers would not accept the job). Note that in this setting it is not important whether the realization of the home productivity shock $x$ is observable to the firm.

\section{Equilibrium}

\subsection{Entry and quit margins}

Equations (3) and (4) provide an expression for the entry margin and the quit margin, as well as a system solving for the cut-off points. See the appendix for details. This system is

$$
\begin{gathered}
\frac{x^{q}-x^{\nu}}{r+\lambda+\delta}=\mathcal{C} \\
x^{q}=y+\frac{\lambda}{r+\lambda+\delta} \int_{x^{\nu}}^{x^{q}} F(z) d z
\end{gathered}
$$

The two margins deserve several comments. The entry margin says that the surplus from the job at $x^{\nu}$ is identical to the entry cost. The quit margin states that home productivity of the marginal worker is equal to the market wage $\left(w^{*}=y\right)$ plus a positive term, which is a hoarding behaviour from workers standpoint. Indeed, workers hold on to existing jobs as a way to save on future $\operatorname{cost} \mathcal{C}$ if home productivity were to fall. This on-the-job hoarding effect generates attachment to the labor market, in the sense that workers quit less than they would do in the absence of entry cost. 


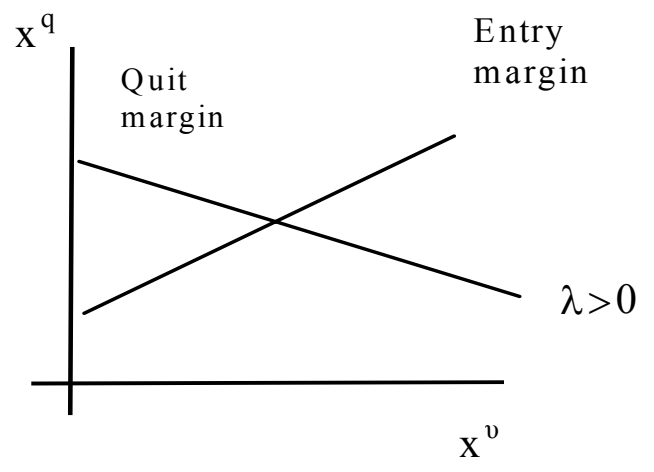

Figure 1: Quit Margin, Entry Margin and Equilibrium Cut-Off Points.

Further notice that as the entry cost disappears, i.e. when $\mathcal{C} \rightarrow 0$, the entry and the quit cut-off points converge to each other. Thus, the existence of the irreversible cost drives a wedge in the two cut-off points. The partial equilibrium is derived in observing that the quit margin is downward sloping in a $\left(x^{\nu}, x^{q}\right)$ space while the entry margin is upward sloping as represented in Figure 1.

The entry curve is upward sloping because a larger $x^{q}$ means longer duration on the job, and thus larger surplus. It is shifted down by higher $\mathcal{C}, r, \delta$ and $\lambda$ : entry is discouraged when $x^{\nu}$ is lower, i.e. there are fewer participants when entry costs are larger or when the surplus is lower, i.e. when the discount of turnover rates are larger.

The quit margin is downward sloping because the hoarding effect is lower, the closer $x^{\nu}$ from $x^{q}$. In the limit $\lambda=0$, the quit margin in horizontal and $x^{q}=w$. Overall, the quit cut-off point $x^{q}$ coincides with wage when $\lambda=0$ or when $\mathcal{C}=0$. The quit margin is shifted up by higher wage $w$ and higher $\lambda$ and reduced by higher $r$ and $\delta$ : the marginal worker is more conservative in quitting (higher $x^{q}$ ) the higher the market wage and the hoarding effect, generated by anticipation of a frequent change in $\lambda$ and less impatience $r+\delta$.

\subsection{Allocation of workers}

An interesting feature of the model is that $y$ shifts the quit curve up but does not affect the entry curve, while $\mathcal{C}$ shifts the entry curve up but leaves the quit curve unchanged. As a result, the cut-off points determining the allocation of workers in home or market activity are both a function of $y$ and $\mathcal{C}$. We think of $y$ and $\mathcal{C}$ as being driven by individual characteristics and aggregate conditions. Notably, $y$ is primarily driven by the skill level of the individual, 
while $\mathcal{C}$ can be thought as a good proxy for the job finding rate, i.e. a combination of frictions and aggregate job creations. We come back on this issue in Section 5. Hereafter, although cut-off points are functions of individual and aggregate parameters $x^{q}(y, \mathcal{C})$ and $x^{\nu}(y, \mathcal{C})$, we neglect to write the arguments for convenience.

Overall, simple comparative statics indicates that

$$
\begin{aligned}
& d x^{q} / d y=d x^{\nu} / d y=\frac{r+\lambda+\delta}{r+\delta+p+q}>0 \\
& d x^{q} / d \mathcal{C}>0 ; d x^{\nu} / d \mathcal{C}<0
\end{aligned}
$$

where $p=\lambda F\left(x^{\nu}\right)$ is the entry rate and $q$ is the quit rate, which can now be determined, i.e. $q=\lambda\left(1-F\left(x^{q}\right)\right)$. The first line states that participation to the labor market is increased along both margins when market productivity is larger relative to home productivity. The second line states that entry costs discourage participation at the entry margins, which is natural, but also that it discourages exits, through the hoarding effect defined above.

There is a natural representation of the allocation of workers in the space $(x, y)$. When $\lambda=0$, this implies that $p=q=0$, and thus the entry and the quit margin are straight lines, as in Figure 2 (the bold straight lines). ${ }^{8}$ When in addition the entry cost $\mathcal{C}$ is zero, both straight lines converge to the 45 degree line, as in the Roy model. In the general case $\lambda>0$, the frontiers of Figure 2 are now concave in $(x, y)$ which is represented with the thinner curves. ${ }^{9}$

\subsection{Stocks}

People in the working age population either have a job or not. If they have a job, they can be in two situations in case of exogenous job destruction; they may want to pay the entry cost to get a new job, in which case they are said to be attached. Or they may not get a new job, and they are said to be unattached.

We denote by $E_{a}$ the number of attached employed and by $E_{n a}$ the number of nonattached employed. Attached employed are those individuals with market production below $x^{\nu}$ while non-attached are those with a job and home productivity between $x^{\nu}$ and $x^{q}$. Upon

\footnotetext{
${ }^{8}$ The figure shows that our model can be seen as an extension of the Roy-model with irreversible entry costs. See Sattinger (2003) for a related extension: he shows that, with search frictions in the two Roysectors, the frontier diverges to two, delimiting space in three parts, one in which workers search in only one sector, one in which they only search in the other, and a third one in which they share time in search in each sector. In our setup, there is no search friction in production of $x$. This asymetry across sectors changes drastically the interpretations of our model compared to Sattinger.

${ }^{9}$ This can be seen in remarking that $d(p+q) / d y=\lambda d x^{q} / d y\left(F\left(x^{\nu}\right)-F\left(x^{q}\right)\right)<0$, so that $x^{q}(y)$ is convex, i.e. $d x^{q} / d y$ calculated above is increasing with $y$.
} 


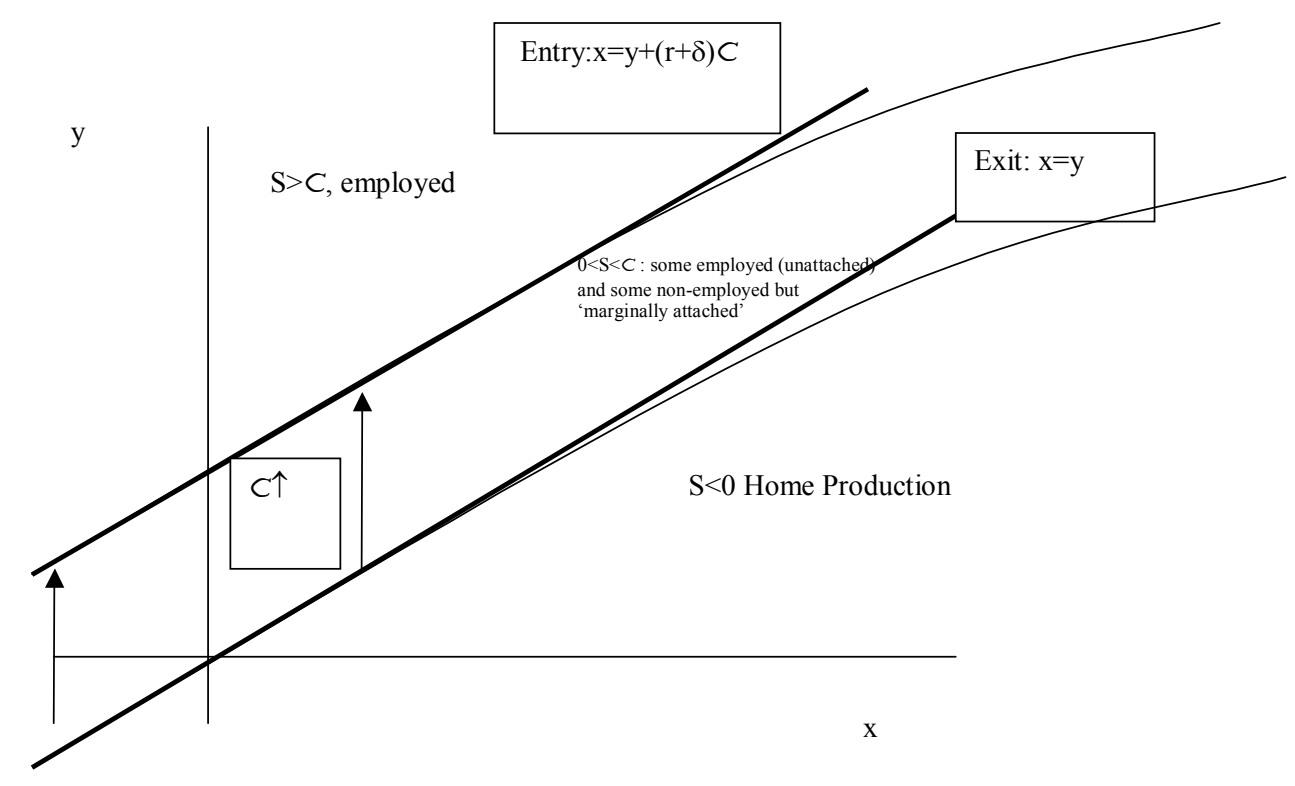

Figure 2: Allocation of Workers as a Function of market $(x)$ and home productivity $(y)$.

losing a job, the unattached are said to be in 'extended unemployed' (they have a value of $x$ between $x^{\nu}$ and $x^{q}$ ) and their number is denoted by $\Sigma$, while non-employed with $x>x^{q}$ are said to be pure non- employed. $N$ is the number of pure non-employed workers. Overall, we have four different states, linked by the identity

$$
\Sigma+E_{n a}+E_{a}+N=1
$$

We shall indicate with $u_{0}=\frac{\delta+q}{p+\delta+q}$ the ratio of exits from employment over total turnover. Recall that $q=\lambda\left(1-F\left(x^{q}\right)\right)$ is the quit rate and $p=\lambda F\left(x^{\nu}\right)$ is the entry rate. Denoting by $\rho$ their complement to $\lambda$, such that $\rho=\lambda-p-q=\lambda F\left(x^{q}\right)-\lambda F\left(x^{\nu}\right)$, we obtain the four stocks (detailed in appendix)

$$
\begin{aligned}
N & =1-F\left(x^{q}\right)=q / \lambda \\
E_{a} & =F\left(x^{\nu}\right)=p / \lambda \\
E_{n a} & =\left(1-u_{0}\right) \rho / \lambda \\
\Sigma & =u_{0} \rho / \lambda
\end{aligned}
$$

Finally, from the attached and non attached employment we get a simple analytical expression for the employment rate

$$
E=E_{a}+E_{n a}=\left(1-u_{o}\right)(1+\delta / \lambda)
$$


which depends on the endogenous variables $\left(x^{q}, x^{\nu}\right)$ and the full set of parameters of the model. Note that in the case $\delta=0$, we have $E=1-u_{0}=p /(p+q)$. Finally, one can easily show that total employment increases with the market productivity $(d E / d y>0)$, while non employment decreases with market productivity $d N / d y<0$, and increases with the entry $\operatorname{cost}(d N / d \mathcal{C}>0)$ Other comparative statics are displayed in appendix.

Having derived the stock, we can define the equilibrium of the model. The equilibrium is a n-ple of 3 endogenous variables $\left(x^{\nu}, x^{q}, w\right)$ determined by

- a quit margin in equation (4);

- a entry margin in equation (3);

- a free entry equation (6)

and 4 stocks $\left(N, E_{a}, E_{n a}, \Sigma\right)$ derived from the two participation margins in a steady-state

\subsection{Flows}

The flows of workers per unit of time between the three states employment, extended unemployment and non-participation can be derived in counting the number of transitions of $x$ into the different intervals $\left[x^{\min }, x^{\nu}\right],\left[x^{\nu}, x^{q}\right]$ and $\left[x^{q}, x^{\max }\right]$. These transitions are respectively at rate $p, \rho=\lambda-p-q$ and $q$ multiplied by the origin population. We can derive the following matrix of flows per unit of time between $E, \Sigma$ and $N$ :

$$
\begin{gathered}
\left(\begin{array}{ccc}
- & E \rightarrow \Sigma & E \rightarrow N \\
\Sigma \rightarrow E & - & \Sigma \rightarrow N \\
N \rightarrow E & N \rightarrow \Sigma & -
\end{array}\right)=\left(\begin{array}{ccc}
- & E_{n a} \delta & E q \\
\Sigma p & - & \Sigma q \\
N p & N \rho & -
\end{array}\right) \\
=\frac{1}{\lambda}\left(\begin{array}{ccc}
- & \delta \rho\left(1-u_{0}\right) & \left.(\delta+\lambda) q\left(1-u_{0}\right)\right) \\
\rho p u_{0} & - & \rho q u_{0} \\
p q & \rho q & -
\end{array}\right)
\end{gathered}
$$

where in the second matrix of the first line the origin population is indicated in symbols, while in the latter matrix we substitute the endogenous value of the stocks described in equations (7), (8), (9) and (10). Note that in addition, the attached employed workers who lose their job at rate $\delta$ could be considered as additional transitions. Notably, if they had to search for a job during an infinity small unit if time, $\Sigma$ would thus include such frictional unemployment and thus one would need to add-up a number $E_{a} \delta=p \delta / \lambda$ of workers to the inflows into $\Sigma$. The same is true for the outflows from $\Sigma$ to employment. 
Table 1: Employment and Extended Unemployment in France and United States, 1996-2000

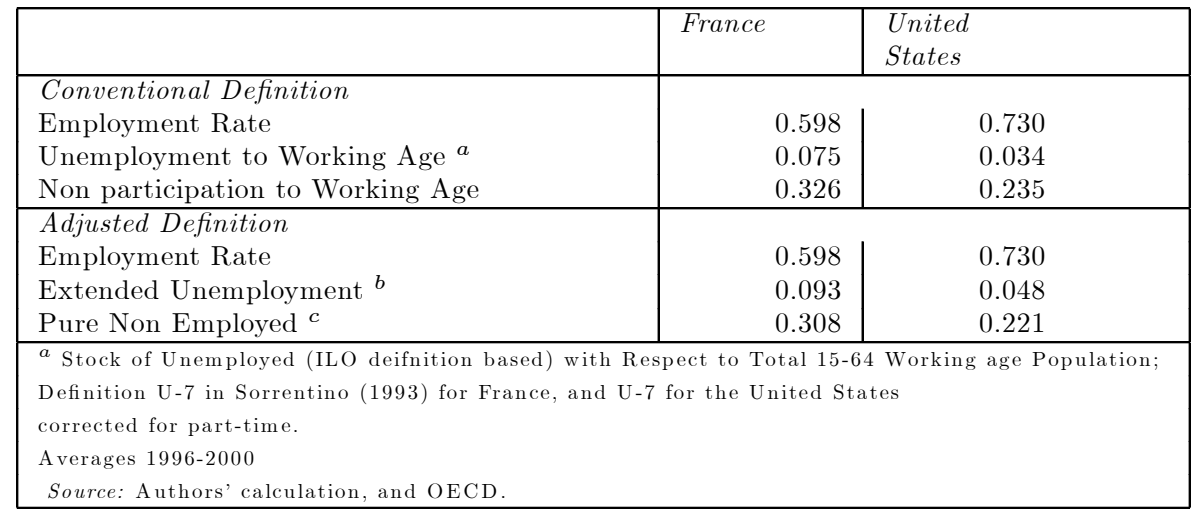

\section{Quantitative exercise}

\subsection{Cross-country differences}

Cross country differences in the employment rate are very large. In this section, we confine our analysis to differences between France and the United States, two countries that are often used for quantitative comparisons between Europe and the United States. In the United States, between 1996 and 2000, 73 percent of the working age population (defined with respect to the 15-64 population) was employed. In France, during the same period, the employment rate was 59.8 percent, with a difference between the two countries of more than 14 percentage points (Table 1). The share of the working age population that is non-employed is conventionally divided into unemployed and non participants, where the distinction is based on the ILO definition of unemployment, which requires that individuals do not have a job, are actively seeking for one, and are immediately available to start working. Unemployment is 7.5 percent of the working age population in France, while it is 3.4 percent in the United States. This suggests that only a third of the differences in employment rate across the two countries is accounted for by the differences in ILO unemployment, with the other two third is accounted for by differences in non participation rate.

In the second part of Table 1, we report the statistics for extended unemployed, a concept of unemployment that is broader than the ILO definition, since it includes all individuals that do not have a job but would like to work. Several scholars, and notably Sorrentino and Jones and Riddel (1999) have shown the existence of a significant number of such individuals in labor force surveys. In two very insightful papers, Sorrentino (1993 and 1995) has established several definitions of unemployment, ranking from 1 (the most conservative) 
to 7 (the broadest one), on the basis of answers of respondents to individual surveys such as their willingness to have a job, the desired number of hours and the duration of the current unemployed spell. The ILO definition corresponds to definition 4, while definition 5 includes part-timers reporting the desire to be full-time and definition 6 additionally includes workers reporting wanting a job but not searching for the job. Sorrentino showed that the discrepancy between rates are substantial, especially in countries such as Italy and Japan. More recently, Jones and Riddel (1999) have shown that in Canada a large fraction of non-employed people would like to work but does not search, and that an unemployment statistics that considers such individuals would be 25 percent larger. In other words, ignoring the issue of part-time (this would imply that we ignore the distinction between U4 and U5), the Canadian rate of extended unemployment U6 would be larger than the ILO rate U4 by $25 \%$. Jones and Ridell qualify these workers marginally attached to the labor market.

Using the estimates of Sorrentino (1993), ignoring the issue of part-time, extended unemployment in the United States is 40 percent larger than the conventional definition, while in France is 20 percent larger. For estimating extended unemployment in the late nineties, we assume that the ratio between extended and conventional unemployment in 1989 is the same as those prevailing in the late part of the nineties. As a result, extended unemployment divided by working age population rise to 5 percent in the United states, and to more than

9 percent in France, even though the differences in the employment rate between the two countries are still accounted for by differences in the share of non employed.

\subsection{Calibration}

In this section we quantitatively account for the differences in the employment rates and non-participation rates between France and the United States, using the simple model presented in the previous sections. The spirit of the exercise is to find parameter values for market productivity and market imperfections so that the model matches the labor market statistics presented in Table 1. In other words, we ask how large must be the average market productivity premium and the market frictions for obtaining the aggregate outcome described in Table 1

Throughout the simulation we set the pure monthly discount rate to 0.005 , and the two turnover statistics $\lambda$ and $\delta$ to 0.15 and 0.09 (Table 2). The distribution is exponential with parameter (and mean) $B=1$, so that the only remaining parameters are $y$ and $\mathcal{C}$. We let the routine searching for values of $\mathcal{C}$ and $y$ so as to match for the United States (France) an employment rate of 73 (59.8) percent and a pure non employment rate of 22.1 (30.8) percent. 
The results are as follows. Market productivity in the United States is calibrated as being 40 percent larger than the average home productivity in the population, and market frictions are set to about a month of market output. Turning to France, our results show that market productivity is roughly equal to average home productivity, while market frictions correspond to 1.6 months of output. These results suggest that institutional settings (such as taxes or transfers to non-participating workers) in the two countries are potentially responsible for huge differences in the market productivity premium. Finally, if we compare the calibrated market productivity between France and the United States, our exercise shows that there is a different in market productivity per worker of 30 percent, exactly as argued by Prescott (2002)

Table 2: Calibration to the US and French Labor Markets

\begin{tabular}{|l|c|c|c|}
\hline Parameters & Notation & United States & France \\
\hline Common Parameters & $r$ & 0.005 & 0.005 \\
\hline Discount Rate & $\lambda$ & 0.15 & 0.15 \\
\hline Idiosyncratic Shock Rate & $\delta$ & 0.09 & 0.09 \\
\hline Separation Rate & $B$ & 1.00 & 1.00 \\
\hline Distribution ${ }^{a}$ & 1.36 & 1.03 \\
\hline Code Determined Parameters & 1.40 & 1.62 \\
\hline Market Productivity & $y$ & 1.17 & 0.78 \\
\hline Market Frictions & $C$ & 0.69 & 0.54 \\
\hline Equilibrium Values & $x^{\nu}$ & 1.18 \\
\hline Entry Margin & $F\left(x^{\nu}\right)$ & 0.78 \\
\hline Quit Margin & $x^{q}$ & 0.69 \\
\hline Calibrated Statistics & $F\left(x^{q}\right)$ & \\
\hline Employment Rate & $E$ & 73.00 & 59.80 \\
\hline Pure Non employment rate & $N$ & 22.10 & 30.80 \\
\hline Extended Unemployment & $\Sigma$ & 4.90 & 9.40 \\
\hline $\begin{array}{l}\text { (a), Distribution is Negative Exponential with parameter } B \\
\text { Source: Authors' calculation }\end{array}$ \\
\hline
\end{tabular}




\section{Applications/extensions}

\subsection{Search theory and unemployment}

In our model, the individuals in the working age population that do not have a job but would like to work are those individuals without a job but with home productivity inside the interval $\left[x^{\nu}, x^{q}\right]$. If these individuals had a job at market productivity $y$, they would accept it, but they are not ready to pay the irreversible entry cost $\mathcal{C}$. As we argued above, our theoretical analysis is thus capturing an important aspect of labor markets, as the work of Sorrentino and Jones and Riddel show that there is a significant number of such workers in labor force surveys. At the same time, we are leaving aside the distinction between the ILO unemployed and the 'marginally attached' workers. This distinction is not crucial to determine the employment rate and the non-participation rate, as we argued above, but is useful to keep a clear view of the labor market. We now filled this gap.

In this section we develop further the concept of entry cost. We argue that the cost $\mathcal{C}$ is only a convenient short-cut for imperfect labor markets that it can easily be interpreted it in terms of search theory. Assume that there is a new state, denoted by $U$, which is a situation in which workers search for a job. Search is time consuming and it is only randomly that workers obtain a job, at a rate $p$. One can thus introduce the value of not-searching, which is denoted by $\widetilde{H}$ where $\sim$ indicates that the derivation of Bellman equations is different from the benchmark model derived in Sections 2 and 3. Similarly, $\widetilde{W}$ will be the value of having a job. For simplicity, we assume that search takes $s$ units of time and thus diverts $s x$ units of home production.

The three value functions read

$$
\begin{aligned}
(r+\lambda) \tilde{W}(x) & \left.=y+\lambda \int \operatorname{Max}\left[W\left(x^{\prime}\right), U\left(x^{\prime}\right), H\left(x^{\prime}\right)\right] d F\left(x^{\prime}\right)+\delta[\operatorname{Max}[U(x), H(x)]-W((x))]\right) \\
(r+\lambda) U(x) & =(1-s) x+p[W(x)-U(x)]+\lambda \int \operatorname{Max}\left[U\left(x^{\prime}\right), H\left(x^{\prime}\right)\right] d F\left(x^{\prime}\right) \\
(r+\lambda) \tilde{H}(x) & =x+\lambda \int \operatorname{Max}\left[U\left(x^{\prime}\right), H\left(x^{\prime}\right)\right] d F\left(x^{\prime}\right)
\end{aligned}
$$

The surplus from the job is now defined by the equation $S(x)=W(x)-\operatorname{Max}[U(x), H(x)]$ where the max operator indicates that the outside option for the worker is either searching for another job or going full-time to home-production. We can easily see that participation decisions along the quit margin, in such a world, are still described by equating the value of 
holding a job and the value of not-searching, i.e.

$$
\begin{aligned}
\widetilde{W}\left(x^{q}\right)-\widetilde{H}\left(x^{q}\right) & =0 \\
U\left(x^{\nu}\right)-\widetilde{H}\left(x^{\nu}\right) & =0
\end{aligned}
$$

The first equation is formally equivalent to (4). Now, the entry margin can be rewritten as $\widetilde{W}\left(x^{\nu}\right)-\widetilde{H}\left(x^{\nu}\right)=\widetilde{W}\left(x^{\nu}\right)-U\left(x^{\nu}\right)$. By difference of (11) and (12) evaluated at $x=x^{\nu}$, we have

$$
s x^{\nu}=p\left[\tilde{W}\left(x^{\nu}\right)-U\left(x^{\nu}\right)\right]
$$

stating that the opportunity cost of search in terms of home production is compensated for the marginally participating worker to the expected return from search. Plugging it into the entry margin, we obtain

$$
\widetilde{W}\left(x^{\nu}\right)-\widetilde{H}\left(x^{\nu}\right)=s x^{\nu} / p
$$

The entry cost of Section 2 and 3 in equation (3) is thus given by $\mathcal{C}=s x^{\nu} / p$. To interpret this result, note that $s x^{\nu}$ is the flow value of forgone home productivity during search, while $1 / p$ is the expected duration of search, so that $\mathcal{C}$ is the expected search cost paid by the worker. Further solving for the two margins, we obtain

$$
\begin{gathered}
x^{q}=y+\frac{\lambda(1-s)}{r+\lambda+\delta+p} \int_{x^{\min }}^{x^{\nu}} F(x) d x+\frac{\lambda}{r+\lambda+\delta} \int_{x^{\nu}}^{x^{q}} F(x) d x \\
\frac{x^{q}-x^{\nu}}{r+\lambda+\delta}=\frac{s x^{\nu}}{p}
\end{gathered}
$$

In the space $\left(x^{\nu}, x^{q}\right)$ one can see that the sign of the slopes of the two margins is the same as in Section 3. The quit margin is even exactly identical when $s=1$. The entry margin has a different slope since $s x^{\nu} / p$ on the right hand-side is depending on $x^{\nu}$.

Overall, these results show that the irreversible entry cost into employment introduced in the previous sections is formally identical to the opportunity cost of time spent searching. The only difference between the two is that the entry cost is paid instantaneoulsy upon entry, while search costs are typically paid on a flow basis. Note also that as the job finding rate goes to infinity, the irreversible entry cost goes to zero: we are back to the competitive labor supply model.

\subsection{Alternative wage determination}

The spirit of most models of equilibrium unemployment is to have a nominal or real rigidity on prices or wages. In contrast, our model, focussing on market participation and unemployment, 
shows that one does not require such rigidities to obtain a non-trivial employment rate: a competitive wage equal to marginal productivity is sufficient here. One might however wonder what is the impact of an alternative wage determination process. In short, when wages are bargained over the total surplus with the employer, the two fundamental equations of the model are very similar. We can show, when $0 \leq \beta \leq 1$ is an index of the bargaining power of workers, that we still obtain the quit margin, and the following modified entry margin:

$$
\begin{gathered}
x^{q}=y+\frac{\lambda}{r+\lambda+\delta} \int_{x^{\nu}}^{x^{q}} F(x) d x \\
\beta \frac{x^{q}-x^{\nu}}{r+\lambda+\delta}=\mathcal{C}
\end{gathered}
$$

In Garibaldi and Wasmer (2003), we also show that the search extension to the model with free entry of firms yields similar results: $\mathcal{C}$ is still equal to $\frac{s x^{\nu}}{p}$ in the above entry margin, while the first integral in equation (15) has to be inserted in the quit margin, slightly modified as follows: $\frac{\lambda(1-s)}{r+\lambda+\delta+\beta p} \int_{x^{\min }}^{x^{\nu}} F(x) d x$.

\subsection{Dual labor markets}

Differences in turnover and attachment to the labor market is one of the main distinctive features of primary and secondary workers in dual labor market theory developed in Doeringer and Piore (1971) and Bulow and Summers (1986). In our model, workers with different value of $x$ have different turnover rate in and out of the labor force. Attached employed workers quit a job and leave the labor market at rate $q=\lambda\left(1-F\left(x^{q}\right)\right)$ : in case of a $\delta$-shock, they remain in the labor market and immediately obtain a new job. On the contrary, unattached employed workers leave the labor market at rate $\delta+q>q$. One can thus identify the attached workers to primary workers and unattached to secondary workers, who further face unemployment from time to time at rate $\delta$.

Dual labor market theory is also based on heterogeneity in market productivity. In our model, assume that there are two classes of workers, one with low $y$, one with high $y$, featuring differences in human capital or training. Then, even though these workers have an identical distribution and frequency of shocks of $x$, the fact that $d x^{q} / d y>0$ and $d x^{\nu} / d y>0$, implies that high productivity workers quit less and overall participate more to the labor market than low productivity workers. Now suppose that $y$ is so large that $x^{q}$ is above $x^{\max }$. In this case, workers never quit the labor market. If in addition, $x^{\nu}>x^{\text {min }}$, then in a steady-state, all workers become employed and none of them are unattached. Figure 3 illustrates. 


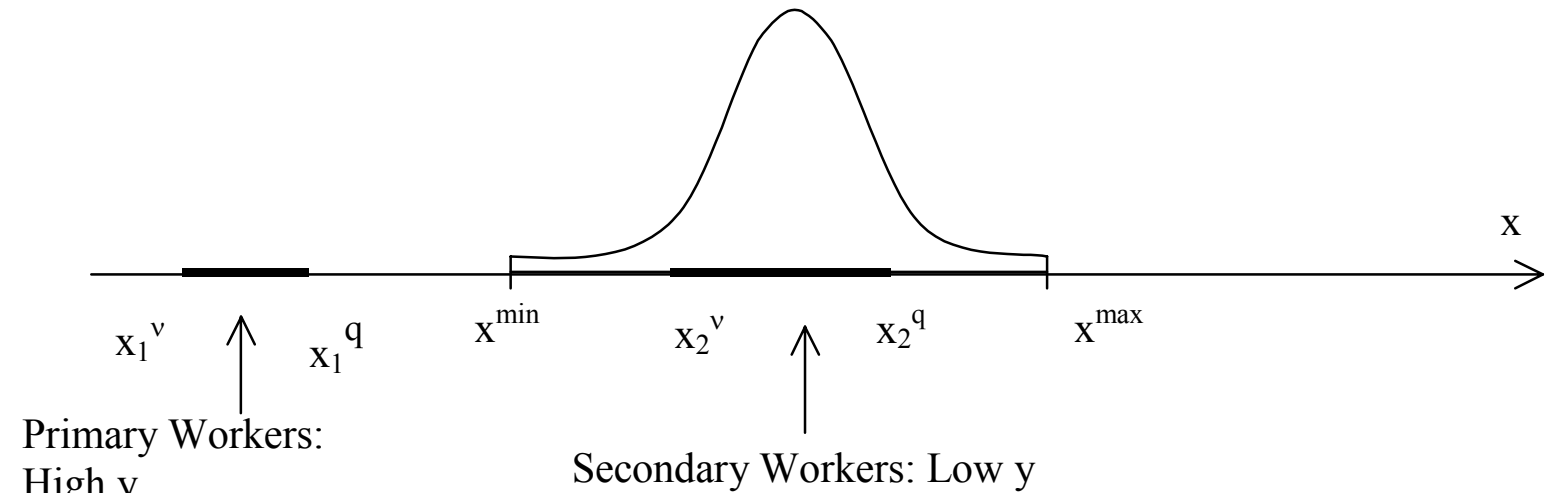

High y

Secondary Workers: Low y

Figure 3: Common home production but different market productivity for two groups of workers. $x_{1}^{q}$ (resp. $x_{2}^{q}$ ) stands for the quit cut-off point of primary (resp. secondary) workers, $x_{1}^{\nu}$ (resp. $x_{2}^{\nu}$ ) stands for the entry cut-off point of primary (resp. secondary) workers.

\subsection{Stochastic heterogeneity in both home and market production}

We now assume that market productivity is also heterogenous and stochastic. Specifically, we assume that an individual is described by a couple $x, y$ where $y$ is market productivity and $x$ is home productivity. While there is a density function $q(x, y)$ in what follows we are mainly interested in the marginal distributions $G(y \mid x)$ and $F(x \mid y)$ that we assume to be continuous with no point mass. We assume that the market productivity $y$ changes at rate $\delta$ and draws a value from $G(y \mid x)$. Similarly, home productivity changes at rate $\lambda$ and its value is drawn from the cumulative $F(x \mid y)$. Shocks to market productivity are independent. It follows that the position of an individual is now described by a couple $x, y$ and that the two value functions read

$$
\begin{aligned}
(r+\lambda+\delta) W(x, y)= & y+\delta \int \operatorname{Max}\left[W\left(x, y^{\prime}\right), H\left(x, y^{\prime}\right)\right] d G\left(y^{\prime} \mid x\right) \\
& +\lambda \int \operatorname{Max}\left[W\left(x^{\prime}, y\right), H\left(x^{\prime}, y\right)\right] d F\left(x^{\prime} \mid y\right) \\
(r+\lambda+\delta) H(x, y)= & x+\delta \int \operatorname{Max}\left[W\left(x, y^{\prime}\right)-\mathcal{C}, H\left(x, y^{\prime}\right)\right] d G\left(y^{\prime} \mid x\right) \\
& +\lambda \int \operatorname{Max}\left[W\left(x^{\prime}, y\right)-\mathcal{C}, H\left(x^{\prime}, y\right)\right] d F\left(x^{\prime} \mid y\right)
\end{aligned}
$$

Under some conditions (see appendix), one can follow Mortensen's (1994) strategy for the proof of existence of a reservation property and then show that this extension is formally equivalent to the previous model, so that the main intuition captured by Figure 2 is preserved here. The surplus from market participation for a $(x, y)$ individual is still defined as $S(x, y)=$ 
$W(x, y)-H(x, y)$. One can define two frontiers in the space $(x, y)$ : the quit frontier is described equivalently by $x^{q}(y)$ or $y^{q}(x)$ and the entry frontier is described equivalently by $x^{\nu}(y)$ or $y^{\nu}(x)$, with

$$
\begin{aligned}
& S\left[x^{q}(y), y\right]=S\left[x, y^{q}(x)\right]=0 \\
& S\left[x^{\nu}(y), y\right]=S\left[x, y^{\nu}(x)\right]=\mathcal{C}
\end{aligned}
$$

\subsection{Aggregate fluctuations}

Mc Donald and Solow (1981) claimed that a good model of unemployment must explain why employment fluctuates while wages remain fix. Taking the second part as given, we can exploit further the search extension above to claim that a source of employment fluctuations lies in variations in $\mathcal{C}$ : in fact, in the spirit of matching models, when job creation is reduced, non-employed workers willing a job face longer spells of unemployment. This reduction in the job finding rate $p$ implies an increase in the opportunity cost of search, i.e. a rise in $\mathcal{C}$. Future works should aim at investigating the dynamics of an economy where the source of business cycles is jointly determined by aggregate fluctuations in both $y$ and $\mathcal{C}$.

\section{Conclusion}

We have developed a simple model of equilibrium employment in imperfect labor markets and discussed a) its ability to account for cross-country differences ; b) its implications to labor market analysis and notably its potential to understand the subtle distinctions between unemployment and non-participation ; and c) its links to search theory and dual labor market theory.

Future work should aim at introducing individual heterogeneity in market productivity and account for aggregate fluctuations and macroeconomic dynamics.

\section{APPENDIX}

\subsection{Entry and quit}

The two Bellman equations can be written as

$$
\begin{aligned}
(r+\delta+\lambda) W(x) & =w+\delta \operatorname{Max}[W(x)-\mathcal{C} ; H(x)]+\lambda \int \operatorname{Max}[W(z), H(z)] d F(z) \\
(r+\lambda) H(x) & =x+\lambda \int \operatorname{Max}[W(z)-\mathcal{C}, H(z)] d F(z)
\end{aligned}
$$


Further adding and subtracting $\delta H(x)$ and $\lambda \int H(z) d F(z)$ from the first equation and $\lambda \int H(z) d F(z)$ from the second equation we obtain

$$
\begin{aligned}
(r+\delta+\lambda) W(x) & =w+\delta H(x)+\delta \operatorname{Max}[S(x)-\mathcal{C} ; 0]+\lambda \int \operatorname{Max}[S(z), 0] d F(z)+\lambda \int H(z) d F(z) \\
(r+\lambda) H(x) & =x+\lambda \int \operatorname{Max}[S(z)-\mathcal{C}, 0] d F(z)+\lambda \int H(z) d F(z)
\end{aligned}
$$

so that

$$
(r+\delta+\lambda) S(x)=w-x+\delta \operatorname{Max}[S(x)-\mathcal{C} ; 0]+\lambda \int \operatorname{Max}[S(z), 0] d F(z)-\lambda \int \operatorname{Max}[S(z)-\mathcal{C}, 0] d F(z)
$$

from which it is immediate to see that the function is piecewise continuous and satisfies the reservation property. Further, the monotonic slope of the surplus functions are

$$
\begin{aligned}
& S^{\prime}(x)=-\frac{1}{r+\lambda} \quad x<x^{\nu} \\
& S^{\prime}(x)=-\frac{1}{r+\lambda+\delta} \quad x>x^{\nu}
\end{aligned}
$$

This shows that the surplus function is continuous and that reservation strategies exists. This implies that

$$
\begin{aligned}
\int \operatorname{Max}[S(z), 0] d F(z) & =\int_{x_{\min }}^{x^{\nu}} S(z) d F(z)+\int_{x^{\nu}}^{x^{q}} S(z) d F(z) \\
\int \operatorname{Max}[S(z)-\mathcal{C}, 0] d F(z) & =\int_{x_{\min }}^{x^{\nu}} S(z) d F(z)-\mathcal{C} F\left(x^{\nu}\right)
\end{aligned}
$$

so that the surplus simplifies to

$$
(r+\delta+\lambda) S(x)=w-x+\delta \operatorname{Max}[S(x)-\mathcal{C} ; 0]+\lambda \int_{x^{\nu}}^{x^{q}} S(z) d F(z)+\lambda \mathcal{C} F\left(x^{\nu}\right)
$$

Further, an integration by part leads to

$$
\int_{x^{\nu}}^{x^{q}} S(z) d F(z)=-S\left(x^{\nu}\right) F\left(x^{\nu}\right)+\frac{1}{r+\lambda+\delta} \int_{x^{\nu}}^{x^{q}} F(z) d z
$$

so that

$$
(r+\delta+\lambda) S(x)=w-x+\delta \operatorname{Max}[S(x)-\mathcal{C} ; 0]+\frac{\lambda}{r+\lambda+\delta} \int_{x^{\nu}}^{x^{q}} F(z) d z
$$

It is then easy to obtain the quit margin using $S\left(x^{q}\right)=0$ in the expression above, while the entry margin is obtained combining $S(x)=\frac{x^{q}-x}{r+\lambda+\delta}$ and $S\left(x^{\nu}\right)=\mathcal{C}$. 


\section{$7.2 \quad$ Stocks}

Proof: equations (7) and (8) are derived from the definition of the density of $x$. Further, we have

$$
\Sigma+E_{n a}=F\left(x^{q}\right)-F\left(x^{\nu}\right)
$$

One then uses the following differential equation for the unemployment people

$$
\begin{aligned}
\partial \Sigma / \partial t & =\delta E_{n a}+(\lambda-p-q) N-(p+q) \Sigma \\
& =0 \text { in a steady-state }
\end{aligned}
$$

which yields equation $(9)$, in adding $(p+q) E_{n a}$ on both sides and replacing $E_{n a}+\Sigma$ by equation (16) to . Equation (10) then comes straightforward.

\subsection{Comparative statics}

Differentiating (Entry) and (Quit), we have

$$
\begin{aligned}
d x^{q}-d x^{\nu} & =d \mathcal{C}(r+\lambda+\delta) \\
d x^{q} & =d y+\frac{(\lambda-q) d x^{q}-p d x^{\nu}}{r+\lambda+\delta}
\end{aligned}
$$

Introducing $\Lambda=\frac{r+\lambda+\delta}{r+\delta+p+q}>0$, we have

$$
\begin{aligned}
\frac{d x^{q}}{d y} & =\frac{d x^{\nu}}{d y}=\Lambda \\
\frac{d x^{q}}{d \mathcal{C}} & =p \Lambda ; \frac{d x^{\nu}}{d \mathcal{C}}=-(r+\delta+q) \Lambda
\end{aligned}
$$

From (7) to (10), we have

$$
\begin{aligned}
d N & =-\lambda f\left(x^{q}\right) d x^{q} \\
d \Sigma & =d u_{0}[1-(p+q) / \lambda]+u_{0}\left[f\left(x^{q}\right) d x^{q}-f\left(x^{\nu}\right) d x^{\nu}\right] \\
d E & =-d u_{0} \\
d u_{0} & =\frac{p d q-(\delta+q) d p}{(\delta+p+q)^{2}}=-\frac{\lambda\left[p f\left(x^{q}\right) d x^{q}+(\delta+q) f\left(x^{\nu}\right) d x^{\nu}\right]}{(\delta+p+q)^{2}}
\end{aligned}
$$

Thus,

$$
\begin{aligned}
& d N / d y<0 ; d N / d \mathcal{C}<0 \\
& d u_{0} / d y<0 ; d u_{0} / d \mathcal{C} \lessgtr 0 \\
& d E / d y>0 ; d E / d \mathcal{C} \lessgtr 0 \\
& d \Sigma / d y \lessgtr 0 ; d \Sigma / d \mathcal{C} \lessgtr 0
\end{aligned}
$$

with unresolved ambiguities. 


\subsection{The Surplus Function with Double Heterogeneity}

When the productivity of an individual is described by a couple $x, y$ and the two value functions read

$$
\begin{aligned}
(r+\lambda+\delta) W(x, y)= & y+\delta \int \operatorname{Max}\left[W\left(x, y^{\prime}\right), H\left(x, y^{\prime}\right)\right] d G\left(y^{\prime} \mid x\right) \\
& +\lambda \int \operatorname{Max}\left[W\left(x^{\prime}, y\right), H\left(x^{\prime}, y\right)\right] d F\left(x^{\prime} \mid y\right) \\
(r+\lambda+\delta) H(x, y)= & x+\delta \int \operatorname{Max}\left[W\left(x, y^{\prime}\right)-\mathcal{C}, H\left(x, y^{\prime}\right)\right] d G\left(y^{\prime} \mid x\right) \\
& +\lambda \int \operatorname{Max}\left[W\left(x^{\prime}, y\right)-\mathcal{C}, H\left(x^{\prime}, y\right)\right] d F\left(x^{\prime} \mid y\right)
\end{aligned}
$$

The surplus from market participation for a $x, y$ individual is $S(x, y)=W(x, y)-H(x, y)$. Summing up the two previous value functions and adding and subtracting $\delta \int H\left(x, y^{\prime}\right) d G\left(y^{\prime} \mid x\right)$, $\left.\lambda \int H\left(x^{\prime}, y\right) d F\left(x^{\prime} \mid y\right), \delta \int H\left(x, y^{\prime}\right) d G\left(y^{\prime} \mid x\right), \lambda \int H\left(x^{\prime}, y\right)\right] d F\left(x^{\prime} \mid y\right)$ the surplus function read

$$
\begin{gathered}
(r+\lambda+\delta) S(x, y)=y-x+\delta \int \operatorname{Max}\left[S\left(x, y^{\prime}\right), 0\right] d G\left(y^{\prime} \mid x\right)+\lambda \int \operatorname{Max}\left[S\left(x^{\prime}, y\right), 0\right] d F\left(x^{\prime} \mid y\right) \\
\quad-\delta \int \operatorname{Max}\left[S\left(x, y^{\prime}\right)-\mathcal{C}, 0\right] d G\left(y^{\prime} \mid x\right)-\lambda \int \operatorname{Max}\left[S\left(x^{\prime}, y\right)-\mathcal{C}, 0\right] d F\left(x^{\prime} \mid y\right)
\end{gathered}
$$

In the specific case where density $g$ is independent of $x$ and density $f$ is independent of $y$, one can apply Mortensen's (1994, pp. 1124-1129) strategy for a proof of existence. Let us approximate the market productivity shock by a finite state Markov process $y_{1}, y_{2}, \ldots, y_{n}$. The idea is to show that for each state, there exists two vectors $\left(x_{i}^{q}\right)$ and $\left(x_{i}^{\nu}\right)$ which are denoted respectively $X^{q}$ and $X^{\nu}$ for which the expression for the surplus, divided by $(r+\lambda+\delta)$ is a contraction that maps the set of piecewise linear functions in $x$ with $2 n$ 'kinks' at values of $x$ equal to the elements of $X^{q}$ and $X^{\nu}$ into itslef. The rest of the proof follows Mortensen quite closely.

\section{References}

[1] Becker, G. (1988) "Family Economics and Macro Behavior" American Economic Review 78:1-13

[2] Bulow, J. and L. Summers (1986) "A Theory of Dual Labor Markets with Applications to Industrial Policy, Discrimination, and Keynesian Unemployment", Journal of Labor Economics 4: 376-414 
[3] Dixit, A. and Pindyck R. (1994) Investment Under Uncertainty Princeton: Princeton University Press

[4] Doeringer, P. and M. Piore (1971) Internal Labor Markets and Manpower Analysis, Lexington, Mass.

[5] Garibaldi, P. and Wasmer, E. (2003) Equilibrium Search Unemployment, Endogenous Participation, and Labor Market Flows, CEPR Working Paper 3986

[6] Jones, S, and Riddel W.C. (1999) "The Measurement of Unemployment: An Empirical Approach" Econometrica Vol. 67, no. 1, 147-162.

[7] Mortensen, D.T. (1994). "The Cyclical Behavior of Job and workers Flows", Journal of Economic Dynamics and Control, 1994, 18, 1121-1142

[8] Mortensen, D. and Pissarides C.A. (1994) "Job Creation and Job Destruction in the Theory of Unemployment, Review of Economic Studies, 61, 397-415.

[9] Mc Donald, Ian and Solow, Robert M. (1981). "Wage Bargaining and Unemployment" American Economic Review, Vol. 71, No. 5. (Dec., 1981), pp. 896-908

[10] Prescott (2002) "Prosperity and Depression: 2002 Richard Ely Lecture", Federal Reserve Bank of Minneapolis Working Paper 618.

[11] Roy, A.D. (1951). "Some Thoughts on the Distribution of Earnings", Oxford Economic Papers, New Series, Vol. 3, No. 2. (Jun., 1951), pp. 135-146.

[12] Sattinger M. (2003). "A Search Version of the Roy Model", mimeo, Univ. at Albany

[13] Shapiro, C. and Stiglitz, J. (1984) "Equilibrium Unemployment as a Worker Discipline Device" American Economic Review, Vol. 74: 433-444

[14] Sorrentino (1993). "International Comparison of Unemployment Indicators", Monthly Labor Review, March, 3-24

[15] Sorrentino C., 1995, "International unemployment indicators, 1983-93", Monthly Labor Review, August. 


\section{IZA Discussion Papers}

\begin{tabular}{|c|c|c|c|c|}
\hline No. & Author(s) & Title & Area & Date \\
\hline 936 & $\begin{array}{l}\text { M. K. Jones } \\
\text { P. L. Latreille } \\
\text { P. J. Sloane }\end{array}$ & Disability, Gender and the Labour Market & 3 & $11 / 03$ \\
\hline 937 & $\begin{array}{l}\text { W. Eggert } \\
\text { L. Goerke }\end{array}$ & $\begin{array}{l}\text { Fiscal Policy, Economic Integration and } \\
\text { Unemployment }\end{array}$ & 2 & $11 / 03$ \\
\hline 938 & $\begin{array}{l}\text { D. Del Boca } \\
\text { A. Venturini }\end{array}$ & Italian Migration & 1 & $11 / 03$ \\
\hline 939 & E. Toulemonde & $\begin{array}{l}\text { Acquisition of Skills, Education Subsidies, and } \\
\text { Agglomeration of Firms }\end{array}$ & 2 & $11 / 03$ \\
\hline 940 & $\begin{array}{l}\text { A. Constant } \\
\text { Y. Shachmurove } \\
\text { K. F. Zimmermann }\end{array}$ & $\begin{array}{l}\text { What Makes an Entrepreneur and Does It Pay? } \\
\text { Native Men, Turks, and Other Migrants in } \\
\text { Germany }\end{array}$ & 1 & $11 / 03$ \\
\hline 941 & $\begin{array}{l}\text { R. V. Burkhauser } \\
\text { J. S. Butler } \\
\text { G. Gumus }\end{array}$ & $\begin{array}{l}\text { Option Value and Dynamic Programming Model } \\
\text { Estimates of Social Security Disability Insurance } \\
\text { Application Timing }\end{array}$ & 6 & $11 / 03$ \\
\hline 942 & $\begin{array}{l}\text { R. V. Burkhauser } \\
\text { J. S. Butler } \\
\text { G. Gumus }\end{array}$ & $\begin{array}{l}\text { Dynamic Modeling of the SSDI Application } \\
\text { Timing Decision: The Importance of Policy } \\
\text { Variables }\end{array}$ & 6 & $11 / 03$ \\
\hline 943 & $\begin{array}{l}\text { J. T. Addison } \\
\text { P. Teixeira }\end{array}$ & $\begin{array}{l}\text { What Have We Learned About the Employment } \\
\text { Effects of Severance Pay? Further Iterations of } \\
\text { Lazear et al. }\end{array}$ & 3 & $11 / 03$ \\
\hline 944 & $\begin{array}{l}\text { H. Görg } \\
\text { D. Greenaway }\end{array}$ & $\begin{array}{l}\text { Much Ado About Nothing? Do Domestic Firms } \\
\text { Really Benefit from Foreign Direct Investment? }\end{array}$ & 2 & $11 / 03$ \\
\hline 945 & $\begin{array}{l}\text { R. Schöb } \\
\text { D. E. Wildasin }\end{array}$ & $\begin{array}{l}\text { Economic Integration and Labor Market } \\
\text { Institutions: Worker Mobility, Earnings Risk, and } \\
\text { Contract Structure }\end{array}$ & 2 & $12 / 03$ \\
\hline 946 & M. Leonardi & $\begin{array}{l}\text { Earnings Instability of Job Stayers and Job } \\
\text { Changers }\end{array}$ & 1 & $12 / 03$ \\
\hline 947 & U. Sunde & $\begin{array}{l}\text { Potential, Prizes and Performance: Testing } \\
\text { Tournament Theory with Professional Tennis } \\
\text { Data }\end{array}$ & 7 & $12 / 03$ \\
\hline 948 & $\begin{array}{l}\text { A. Kugler } \\
\text { G. Pica }\end{array}$ & $\begin{array}{l}\text { Effects of Employment Protection and Product } \\
\text { Market Regulations on the Italian Labor Market }\end{array}$ & 6 & $12 / 03$ \\
\hline 949 & C. J. Flinn & $\begin{array}{l}\text { Minimum Wage Effects on Labor Market } \\
\text { Outcomes under Search with Bargaining }\end{array}$ & 6 & $12 / 03$ \\
\hline 950 & $\begin{array}{l}\text { P. Garibaldi } \\
\text { E. Wasmer }\end{array}$ & $\begin{array}{l}\text { Equilibrium Employment in a Model of Imperfect } \\
\text { Labor Markets }\end{array}$ & 1 & $12 / 03$ \\
\hline
\end{tabular}

An updated list of IZA Discussion Papers is available on the center's homepage www.iza.org. 